\title{
Factors Affecting Knowledge Sharing Using ViRTUAL Platforms - A VAlidation OF UNIFIED TheORY of ACCEPTANCE ANd USE OF TECHNOLOGY (UTAUT)
}

\author{
HairolAdenanKasim \\ Faculty of Information Management, MARA Technology University, Shah Alam, \\ Malaysia
}

\begin{abstract}
Knowledge sharing is an important initiative in creating competitive advantage. As an important tool in the successful implementation of Knowledge Management (KM), sharing knowledge is seen to be the most important practice and resource which organization possesses. Various organizations have developed strategies to ensure that KM is successful by embedding knowledge sharing practices in their routine work processes. Nowadays, people have been using virtual platforms and web-based technologies, such as Internet, Intranet, blogs, social media, and other online technology, for sharing knowledge and information. The purpose of this study is to evaluate factors that can inculcate knowledge sharing behavior using the virtual platforms. Therefore, this study will adopt Unified Theory of Acceptance and Use of Technology (UTAUT) to investigate the key factors on this sharing behavior. The UTAUT model adopted in this paper is empirically tested on a sample of 510respondents, and significant relationships among these constructs were found.
\end{abstract}

\section{KEYWORDS}

Knowledge Sharing,Knowledge Management, Virtual platforms, Web-Based, UTAUT.

\section{INTRODUCTION}

Knowledge management (KM) has been widely initiated and practiced in various organizations around the world. The KM initiative comprises a range of strategies and approaches to identify, develop, acquire, transfer, share, and enable adoption of wisdom and experiences, by either individuals or organizations. KM's definition has been suggested by several academicians, including Argote et al. (2000) and Huber (1991), who refer to KM as how organizations create, retain, and share knowledge. Landline and Zollo (2007) have described KM as the methods of developing, capturing, and adopting knowledge to enhance organizational performance. These scholars have also asserted this initiative as a range of approaches and procedures exploited by businesses to determine, represent, and transfer information, skills, experience, intellectual property, and other forms of knowledge for innovation and learning across the organization. In line with this argument, KM has been positioned as a business strategy that advances knowledge as a critical resource and can integrate pieces of this knowledge across the organization as a distinguishing feature for market success (Davenport \&Prusak, 1998; Grant, 1996).Furthermore, 
KM also supports the development, classification, utilization, and sharing of knowledge to assist situational understanding and decision making (Ismail \& Raja Abdullah, 2011).

From the above definitions, the academicians have identified knowledge sharing as one of the important pillars in KM. Grant (1996) has asserted that knowledge sharing as an important focus in the KM field, where knowledge is seen as the most important resource an organization can possess. Argote et al. (2000) have defined knowledge sharing as the process through which a unit, group, or division is influenced by the experience or skill of another. These scholars also indicate that the sharing of knowledge can be observed through variances in knowledge or performance of recipient units. Recently, various organizations have developed strategies to ensure that KM is successful by embedding knowledge sharing practices in their routine work processes. In fact, the management and the stakeholders of the companies have realized the importance of sharing practices for their staff and have embedded KM initiatives in their organizations.

An organization experiences several advantages and benefits to performing knowledge sharing practices. Knowledge sharing is important because an individual's knowledge will not have much impact for the business unless it is available to other individuals (Nonaka\& Takeuchi, 1995). Knowledge sharing behavior has facilitated learning among employees and enable them to resolve problems related to situations encountered by their colleagues in the past, allowing for quicker responses to the business needs (Sher\& Lee, 2004). Therefore, knowledge sharing practices will allow product and technical innovation, especially for research organizations, and this will lead to new product development to accommodate customer needs (Calantone et al., 2002). The practices of learning and sharing knowledge among employees would improve organizational capabilities and firm performance in terms of cost reduction, accomplishment of new products, and growth of market share (Sher\& Lee, 2004).

Nowadays, people have been using virtual platforms and web-based technologies, such as Internet, Intranet, blogs, social media, and other online technology, for sharing knowledge and information. These are the media through which knowledge or information are acquired, transferred, shared, and disseminated using the recent network architecture and technology. In relation to this, previous scholars have identified virtual mode as an effective platform for knowledge sharing and collaboration. Dubé (2006) has defined the new mode: virtual community platforms in which members use Information and Communication Technology (ICT) as the primary media of interaction. Lin (2008) has proposed virtual communities as a cyberspace community that has several internet-based forms of chat and collaboration, such as discussion forums, chatting space, social media, or online bulletin boards. These online applications share several common features, including collaboration elements that support members in different time zones and areas. They create non-volatile data and record collaboration that is stored in text and enhanced by multimedia additions.

Promoting knowledge sharing behavior is a challenge for most knowledge-based organizations. Developing a behavior that values and practices knowledge sharing is an effort involving attention to social, technological, organizational, and user attitude or behavior. Previous studies have often assumed that implementing technology, such as virtual platforms, will be enough to promote knowledge sharing. While this intention has been revealed as an ineffective approach, frequently, most of companies' knowledge resources are assigned to technology and not to other factors that stimulate knowledge sharing (Davenport \&Prusak, 1998). Based on previous studies, several gaps or barriers have been acknowledged by recent scholars regarding knowledge sharing, including functional silos, ineffective means of knowledge capture, inadequate technology, 
internal competition, and management gaps in the organization. Prior researchers have proposed several common reasons given by individuals who are reluctant to share their knowledge, such as pride syndrome because the individuals have pride to seek advice or assistance from their peers and wanted to discover new ways for themselves (Davenport \&Prusak, 1998). In addition, Massey et al. (2002) have indicated other reasons, which include not realizing how useful particular knowledge is to others because the individuals might have knowledge used in one situation and do not realize that their colleagues might face a similar situation at a different venue or time. Therefore, the main purpose of this study is to investigate factors inculcating knowledge sharing behavior through the virtual platforms.

\section{UTAUT AND RESEARCH MODEL}

Unified Theory of Acceptance and Use of Technology (UTAUT) model is formulated by Venkatesh and others to explain user intentions to use an information system and subsequent usage behavior. In this theory, several independent variables are re-classified, but retained the core of the original Theory of Reasoned Action (TRA) and Technology Acceptance Model (TAM) in predicting the technology acceptance (Venkatesh et al., 2003). In this model, Venkatesh and Bala (2008) have proposed 12 independent variables, but retained the core of the original TAM model, including Perceived Usefulness (PU) and Perceived Ease-of-Use (PEOU). This model could provide a significantly higher percentage of technology innovation success and proclaimed to be up to $70 \%$ accurate at predicting user acceptance of ICT innovations (Moran et al., 2010; Venkatesh et al., 2003).

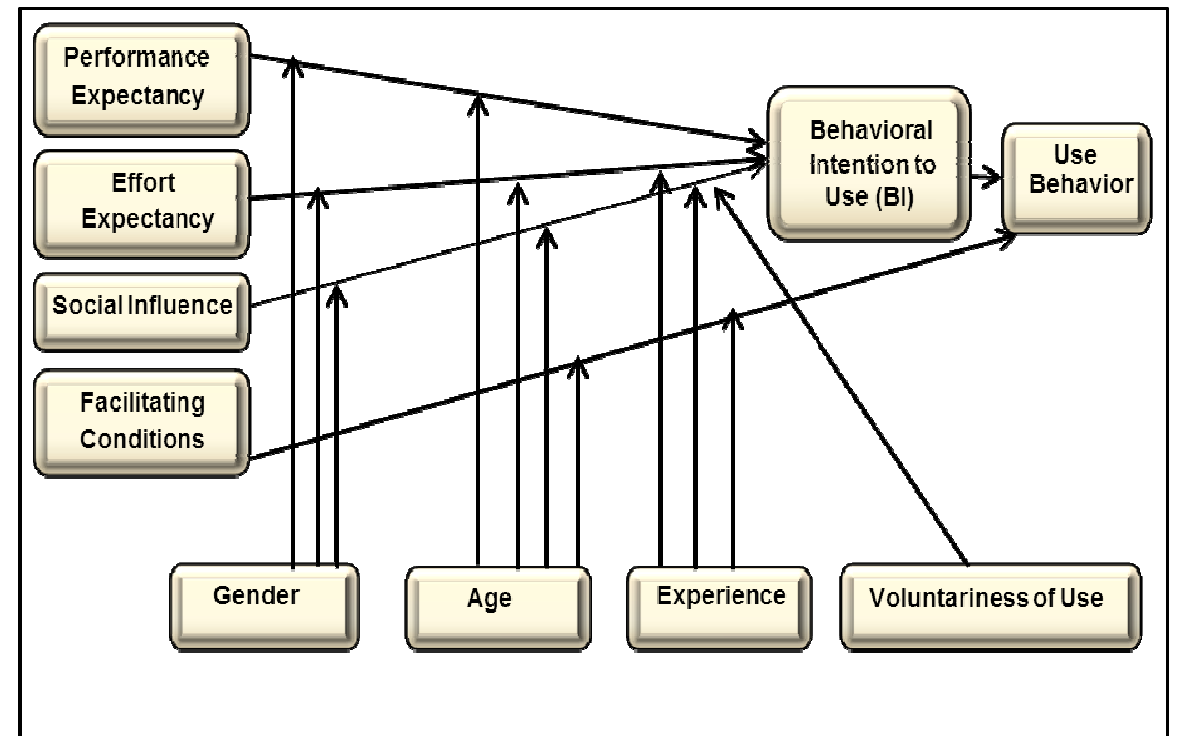

Figure 1: Unified Theory of Acceptance and Use of Technology (UTAUT) model

To date, Unified Theory of Acceptance and Use of Technology (UTAUT) model has served and applied to various technologies-related studies in both organizational and non-organizational contexts and settings. In relation to this, Venkatesh et al. (2012) have asserted that several extensions and integrations of the entire model or part of the model has been developed to reclaim its generalizability, which include extensions that analyzed UTAUT in new technologies setting, new user populations and new cultural environment. Moreover, the extensions also include new 
and additional constructs to expand the scope of the independent variables and inclusion of dependent predictors of the model variables (Venkatesh et al., 2012). Hence, the extensions and replications of the model have worthwhile and relevant in expanding the understanding of technology acceptance and the theoretical boundaries of the UTAUT model. Nevertheless, although this model provides a better understanding for technology acceptance and adoption, the initial UTAUT model only focused on large organizations (Marchewka et al., 2007). Additionally, these experts also indicate that the scales used in this model are still new, and the relevancy of these scales needs to be further tested and verified.

UTAUT model is developed through review and consolidation of constructs of eight models that earlier research has employed to explain IS usage behavior (Venkatesh et al., 2003, 2012). The eight models are Theory of Reasoned Action (TRA), Technology Acceptance Model (TAM), Theory of Planned Behavior (TPB), Motivational Model, Combined Theory of Planned Behavior and Technology Acceptance Model, Model of Personal Computer Utilization, Innovation Diffusion Theory and Social Cognitive Theory.

In general, UTAT theory has four main variables based on the consolidation of the constructs of eight models that earlier research has employed, as follows:

\section{a. Performance Expectancy}

This variable refers to a level that an individual believes that using the system can improve performance (Venkatesh\& Davis 1996; Venkatesh et al., 2003). These scholars have arranged five additional dimensions from previous studies, i.e. Perceived usefulness (Technology acceptance model), external motivation (Motivational Model), work correlation (Model of Personal Computer Utilization), relative advantage (Innovation Diffusion Theory) and expectancy to the achievement (Social cognitive theory). From these dimensions, the author also suggested that this variable referred as the ability to obtain significant rewards after using the system.

b. Effort Expectancy

This component refers to the perceived easiness that an individual thinks of when using the system (Venkatesh and Davis 1996). In addition, these experts have identified three subdimensions of the previous research, which include consciousness of easy to use (Technology Acceptance Model), systematic complexity (Model of Personal Computer Utilization) and operating simplicity (Innovation Diffusion Theory). These authors have suggested that whether the design of the system, such as virtual platforms can allow the user to navigate it easily or not is one of the key success factors of accepting the technology.

c. Social Influence

This variable refers to the level that individual senses that the person who is important to him/her thinks that he/she should use the new system (Venkatesh\& Davis, 1996). With this component, Venkatesh et al. (2003) has categorized three sub-dimensions from the previous scholar - Subjective Norm (Theory of Reasoned Action, Technology Acceptance Model and Theory of Planned Behavior), Public Image (Innovation Diffusion Theory) and Social Factor (Model of Personal Computer Utilization). Furthermore, the effect of social influence depends on environmental settings, which include compulsory or voluntary, and in another context, either in individual or organizational settings (Karahanna\& Straub, 1999, Hartwick\&Barki, 1994). 
International Journal of Managing Public Sector Information and Communication Technologies (IJMPICT) Vol. 6, No. 2, June 2015

\section{d. Facilitating Conditions}

This variable can be described as the level of supporting that an individual received from the organizational and technical relevant equipment toward system use, such as training, manual, hands-on and others (Venkatesh\& Davis 1996). These scholars have categorized three subdimensions from previous models - Control of conscious behavior (Technology Acceptance Model and Theory of Planned Behavior), Promoting condition (Model of Personal Computer Utilization) and Compatibility (Innovation Diffusion Theory).

Other factors, such as gender, age, experience and voluntaries of use are issued to moderate and strengthen the relationship of the four key variables on usage intention and behavior. Venkatesh et al. (2003) have asserted that the purpose of these moderating variables is to emphasize that there is a difference between personal acceptance and strategy of using the system under different environment and situation. These experts also suggest that the purpose of this model is to weigh the introduction of the new technology, such as virtual platforms in the organization and predict and explain the user's behavior of accepting this new system. On that note, this research uses the above theories as the foundation of the proposed hypotheses of this study. Eventually, the research hypotheses are shown below. All the constructs and hypotheses in the research model are adopted and adapted based on UTAUT model, but have been revised to suit the scopes and objectives of this study.

H1: User's performance expectancy has a positive effect on knowledge sharing behavior

H2: User's effort expectancy has a positive effect on knowledge sharing behavior

H3: User's social influence has a positive effect on knowledge sharing behavior

H4: User's facilitating conditions have a positive effect on knowledge sharing behavior

H5a: Age has a significant difference towards knowledge sharing behavior.

H5b: Gender has a significant difference towards knowledge sharing behavior.

H5c: Experience has a significant difference towards knowledge sharing behavior.

\section{RESEARCH METHODOLOGY}

This study will adapt the Quantitative method for the collection of data from the selected respondents. Therefore, this research will adapt the Post Positivist paradigm that will study the behavior and actions of human. As define by Creswell (2009), this research paradigmholds a philosophy in which causes probably determine effects and outcomes. Thus, the problems studied using this approach will reflect requirement to identify and asses the causes that influence outcomes. Post Positivist paradigm also emphasizes meaning of new knowledge to support social movements that aspire to change the environment and contribute towards social justice (Ryan, 2006). This research will use Quantitative approach for the collection and analysis of data by conducting surveys and questionnaires from related participants in the Research and Development (R\&D) organization. This method will focus on related variables or factors with the purpose of formulating a theory or conceptual framework at the conclusion of this research (Sekaran, 2006). A survey provides numeric report of attitudes or behaviors through the exploration of a sample of population with the intention of generalizing the hypotheses of the study (Creswell, 2009). 


\subsection{Population and Sampling}

The participant of this study is the respondents from five R\&D organizations which could assist in generating meaningful information and explanation to fulfill the objectives of this research. The list of respondents obtained from the respective research organizations is the basic population and Stratified Random Sampling technique will be used. This sampling design will provide the most efficient technique when differentiated information is needed regarding various strata within the population. According to Sekaran (2006), this sampling technique will involves a process of segregation, followed by random selection of subjects from each stratum. The population of participants will be divided into mutually exclusive groups that are relevant, appropriate and meaningful in the context of this study.

This research has distributed hardcopy of the survey to 150 respondents and uploaded the formatted electronic version of the survey to 360 participants. The hardcopy and link of this website were distributed to a total of 510 participants, of which 220 responded to the survey.

Table 1: Total Respondents

\begin{tabular}{|l|l|l|l|l|}
\hline No & R\&D Organization & Total Population & Total Respond & Percentage (\%) \\
\hline 1 & Petronas & 130 & 60 & 46.1 \\
\hline 2 & TenagaNasionalBerhad & 80 & 34 & 42.5 \\
\hline 3 & SIRIM & 100 & 39 & 39 \\
\hline 4 & Nuclear Malaysia & 150 & 68 & 45.3 \\
\hline 5 & Green Technology Malaysia & 50 & 19 & 38 \\
\hline & TOTAL & $\mathbf{5 1 0}$ & $\mathbf{2 2 0}$ & $\mathbf{4 3 . 1}$ \\
\hline
\end{tabular}

Based on Table 1, the target respondents are drawn from total population of 510 participants from five organizations and 220 have responded to the circulated survey. The total respond or questionnaire returns for this research was on target since more than 40 percent (\%) of the targeted respondent or more than 200 users had given the feedback on the questionnaires that had been circulated. The response rate of more than $40 \%$ are also consistent and equal to sample size decision model that is proposed by Krejcie and Morgan (1970) and Sekaran (2006).

\section{Data Analysis}

\subsection{Descriptive Statistical Analysis}

The descriptive analysis involved all constructs or variables in this research. This analysis had determined the mean score and standard deviation value for all constructs. This analysis had been split into four parts, to justify the relevant factors that can inculcate knowledge sharing behavior:

\section{a. Performance Expectancy Factor}

As described in Table 2, majority of respondents $($ mean $=4.09)$ believe virtual platforms enable them to retrieve knowledge needed for problem solving, decision making and learning. On the other hand, the use of virtual platforms to promote innovativeness and creativity has the lowest score $($ mean $=3.99)$ in sharing knowledge through the virtual environment. The standard deviations also show consistent variation or dispersion. 
International Journal of Managing Public Sector Information and Communication Technologies (IJMPICT) Vol. 6, No. 2, June 2015

Table 2: Performance Expectancy Factor

\begin{tabular}{|l|l|l|}
\hline & Mean & Std. Deviation \\
\hline a. Virtual platforms are very useful in my job. & 4.06 & .690 \\
\hline b. Virtual platforms enable me to accomplish tasks more quickly. & 4.07 & .725 \\
\hline $\begin{array}{l}\text { c. Virtual platforms will enable me to acquire knowledge from the right } \\
\text { people and time in my organization }\end{array}$ & 4.05 & .719 \\
\hline $\begin{array}{l}\text { d. Virtual platforms will enable me to retrieve knowledge needed for } \\
\text { problem solving, decision making and leaming }\end{array}$ & 4.09 & .711 \\
\hline e. Virtual platforms will improve the quality of my research & 4.01 & .703 \\
\hline f. Virtual platforms will promote innovativeness and creativity & 3.99 & .696 \\
\hline
\end{tabular}

\section{b. Effort Expectancy Factor}

As shown in Table 3, majority of respondents believe virtual platforms are easy to use and this item has the highest score (mean $=4.03$ ) for Effort Expectancy Factor. On the contrary, they also believe not everyone can use the virtual platforms without any difficulties and this item has the lowest score (mean $=3.58$ ) in promoting the virtual knowledge sharing behavior. The standard deviations also show consistent variation or dispersion.

Table 3: Effort Expectancy Factor

\begin{tabular}{|l|l|l|}
\hline & Mean & Std. Deviation \\
\hline a. Virtual platforms are easy to use. & 4.03 & .574 \\
\hline b. My interaction with Virtual platforms is clear and easy to understand & 3.86 & .600 \\
\hline c. Leaming how to utilize the Virtual platforms is not difficult to me & 3.92 & .573 \\
\hline $\begin{array}{l}\text { d. I can easily become skillful in using Virtual platforms in a short period of } \\
\text { time }\end{array}$ & 3.79 & .704 \\
\hline $\begin{array}{l}\text { e. The user interface of the Virtual platforms is easy for me to be familiar } \\
\text { with }\end{array}$ & 3.79 & .645 \\
\hline f. Anyone can use virtual platforms without any difficulties & 3.58 & .771 \\
\hline
\end{tabular}

\section{c. Social Influence Factor}

As illustrated in Table 4, the respondents believe all organization should encourage the use of the virtual platforms for their organizations to promote the virtual knowledge sharing behavior (mean $=4.06$ ). On the contrary, they also believe the Senior Management hasn't encouraged them to use the virtual platforms and this item has the lowest score $($ mean $=3.65)$. The standard deviations also show consistent variation or dispersion.

Table 4: Social Influence Factor

\begin{tabular}{|l|l|l|}
\hline & Mean & Std. Deviation \\
\hline a. My superior is very supportive in the use of the Virtual platforms & 3.72 & .701 \\
\hline b. The Senior Management encourages me to use the Virtual platforms. & 3.65 & .799 \\
\hline c. My colleagues have been help ful in the use of the Virtual platforms. & 3.76 & .688 \\
\hline d. My research community has influence me to use the Virtual platforms & 3.74 & .784 \\
\hline e. My organization has supported the use of Virtual platforms. & 3.74 & .732 \\
\hline f. All organization should encourage the use of the virtual platforms & 4.06 & .601 \\
\hline
\end{tabular}


International Journal of Managing Public Sector Information and Communication Technologies (IJMPICT) Vol. 6, No. 2, June 2015

\section{d. Facilitating Condition Factor}

Based on Table 5, most of the respondents believe all organization should give full support to use the virtual platforms to promote the knowledge sharing behavior (mean $=4.09$ ). However, the participants also believe users' guides (manuals) related to virtual platforms are still insufficient to promote the virtual knowledge sharing behavior (mean $=3.38$ ). The standard deviations also show consistent variation or dispersion.

Table 5: Facilitating Condition Factor

\begin{tabular}{|l|l|l|}
\hline & Mean & Std. Deviation \\
\hline $\begin{array}{l}\text { a. My organization always support whenever I acquire a virtual platforms } \\
\text { training }\end{array}$ & 3.45 & .774 \\
\hline $\begin{array}{l}\text { b. A specific person (or group) is always available to assist me in using the } \\
\text { virtual platforms }\end{array}$ & 3.53 & .794 \\
\hline $\begin{array}{l}\text { c. User guides (manual) related to the Virtual platforms are always } \\
\text { available for me }\end{array}$ & 3.38 & .834 \\
\hline $\begin{array}{l}\text { d. There are sufficient facilities (hardware and software) for the Virtual } \\
\text { platforms }\end{array}$ & 3.51 & .782 \\
\hline $\begin{array}{l}\text { e. Virtual platforms have the necessary functions and capabilities for } \\
\text { sharing knowledge }\end{array}$ & 3.88 & .621 \\
\hline f. All organizations should give full support to use the virtual platforms & 4.09 & .634 \\
\hline
\end{tabular}

\subsection{Multivariate Analysis}

Multivariate analysis was the method for testing the research's hypotheses that includes Confirmatory Factor Analysis (CFA), Structural Equation Modeling (SEM) and Multivariate Analysis of Variance (MANOVA). CFA and SEM are recognized to provide rigorous analysis of model power in relation to construct and content validity. CFA is a multivariate statistical procedure in research design stages that are used to test how well the measured variables represent the number of constructs. According to Raykov and Marcoulides (2008), the main objective in CFA lies in examining the pattern of relations among the factors, as well as those between them and the observed variables. Afterwards, after the measurement model has been analyzed using SEM, the next step is to evaluate the moderator variables (age, gender and experience) using Multivariate Analysis of Variance (MANOVA). This technique can measure the differences for two or more dependent variables based on a set of categorical or non-metric variables acting as independent variables (Hair et al., 2010).

\subsubsection{Confirmatory Factor Analysis (CFA) a. Performance Expectancy Factor}

CFA for the independent variable - Performance Expectancy is performed to analyze how well the measured variables represent the number of constructs.A CFA is conducted for this factor to determine whether the indicators measured the constructs and are assigned adequately. 
International Journal of Managing Public Sector Information and Communication Technologies (IJMPICT) Vol. 6, No. 2, June 2015

Table 6: Performance Expectancy Indexes

\begin{tabular}{|l|l|l|l|}
\hline Fit Indices & Recommended Level $* *$ & Output Value & Summary \\
\hline $\mathrm{P}$ value $\left(\mathrm{X}^{2}\right)$ & Not significant $\mathrm{p}>0.05$ & .000 & Not Accepted \\
\hline $\mathrm{X}^{2} / \mathrm{df}$ & $<3.0$ & 75.8 & Not Accepted \\
\hline GFI & $\geq 0.80$ & .89 & Accepted \\
\hline AGFI & $\geq 0.80$ & .74 & Not Accepted \\
\hline NFI & $\geq 0.80$ & .89 & Accepted \\
\hline CFI & $\geq 0.90$ & .90 & Accepted \\
\hline RMSEA & $<0.10$ & .19 & Not Accepted \\
\hline
\end{tabular}

**Source: Medsker et al. (1994), Doll et al. (1994), Bentler et al. (1995) and Hair et al. (2010)

Table 6 summarizes the results of these tests. Empirical evidence in CFA is generally assessed using criteria, such as the Comparative Fit Index (CFI), Normed Fit Index (NFI), Goodness-of-fit index (GFI), Adjusted Goodness-of-fit index (AGFI) and Root Mean-Squared Error Approximation (RMSEA). As indicated by Bentler (1995), a CFI value greater than 0.90 indicates an acceptable fit to the data. An analysis of the Table 6 for this study reveals that the CFI value (0.901) is acceptable, which suggests a good model fits. As for convergent validity, NFI values of 0.80 or greater indicate an adequate model fit (Bentler, 1995). Thus, the NFI value (0.89) shown in Table 6 indicates an adequate model fit for this study. In addition, a GFI value that exceeds 0.80 indicates a good model (Doll et al., 1994). As a result, the GFI value (0.89) revealed in Table 6 indicates a good model for this study. According to Doll et al. (1994), AGFI values of 0.80 or greater indicates an adequate model fit. On the contrary, the AGFI for this study is below the threshold (0.74) and not indicates a good model for this study. As for RMSEA, a value of about 0.10 or less would indicate a close-fit of the model in relation to the degrees of freedom (Hair et al., 2010). On the other hand, the RMSEA for this factor is above the threshold (0.19) and not indicates a good model for this study.

Furthermore, to ensure that the measurement model fit and suitable for this study, Performance Expectancy indexes are examined. Hair et al. (2010) have suggested that if three or four indexes are accepted, this measurement model is recommended for further analysis. Therefore, as described in summary of Table 6, the model has three accepted indexes that indicate Performance Expectancy measurement model is suitable for this study.

\section{b. Effort Expectancy}

CFA for the second independent variable (Effort Expectancy) is performed to analyze how well the measured variables represent the number of constructs.

Table 7: Indexes Effort Expectancy

\begin{tabular}{|l|l|l|l|}
\hline Fit Indices & Recommended Level** & $\begin{array}{c}\text { Output } \\
\text { Value }\end{array}$ & Summary \\
\hline $\mathrm{X}^{2}$ & Not significant $\mathrm{p}>0.05$ & .000 & Not Accepted \\
\hline $\mathrm{X}^{2} / \mathrm{df}$ & $<3.0$ & 0.26 & Accepted \\
\hline GFI & $\geq 0.80$ & 0.99 & Accepted \\
\hline AGFI & $\geq 0.80$ & 0.99 & Accepted \\
\hline NFI & $\geq 0.80$ & 0.99 & Accepted \\
\hline CFI & $\geq 0.90$ & 1.00 & Accepted \\
\hline RMSEA & $<0.10$ & 0.00 & Accepted \\
\hline
\end{tabular}


International Journal of Managing Public Sector Information and Communication Technologies (IJMPICT)

Vol. 6, No. 2, June 2015

**Source: Medsker et al. (1994), Doll et al. (1994), Bentler et al. (1995) and Hair et al. (2010)

A CFA is conducted for these constructs to determine whether the indicators measured the constructs and are assigned adequately. As revealed in Table 7, CFI value (1.000),NFI value (0.89), GFI value (0.99), AGFI value (0.99) and RMSEA value (0.00) indicates adequate model fit and are acceptable for this study. In addition, to ensure that the measurement model fit and suitable for this study, the relevant indexes are examined. Hair et al. (2010) have suggested that if three or four indexes are accepted, this measurement model is recommended for further analysis. Thus, as described in summary for Table 7, the model has six accepted indexes that indicate Effort Expectancy measurement model is suitable for this study.

\section{c. Social Influence}

CFA for the third independent variable - Social Influence is performed to analyze how well the measured variables represent the number of constructs.

Table 8: Indexes Social Influence

\begin{tabular}{|l|l|l|l|}
\hline Fit Indices & Recommended Level $^{* *}$ & Output Value & Summary \\
\hline $\mathrm{X}^{2}$ & Not significant $\mathrm{p}>0.05$ & .000 & Not Accepted \\
\hline $\mathrm{X}^{2} / \mathrm{df}$ & $<3.0$ & 8.57 & Not Accepted \\
\hline GFI & $\geq 0.80$ & .96 & Accepted \\
\hline AGFI & $\geq 0.80$ & .79 & Not Accepted \\
\hline NFI & $\geq 0.80$ & .96 & Accepted \\
\hline CFI & $\geq 0.90$ & .97 & Accepted \\
\hline RMSEA & $<0.10$ & .19 & Not Accepted \\
\hline
\end{tabular}

**Source: Medsker et al. (1994), Doll et al. (1994), Bentler et al. (1995) and Hair et al. (2010)

A CFA is conducted for these constructs to determine whether the indicators measured the constructs and are assigned adequately. As described in Table 8, CFI value (0.97), NFI value (0.96), and GFI value (0.96) indicates adequate model fit and are acceptable for this study. On the contrary, AGFI value (0.79) and RMSEA value (0.19) are below the recommended level and not adequate as model fit.Furthermore, to ensure that the measurement model fit and suitable for this study, Social Influence indexes are examined. Hair et al. (2010) have suggested that if three or four indexes are accepted, this measurement model is recommended for further analysis. Therefore, as described in summary of Table 8, the model has three accepted indexes that indicate Social Influence measurement model is still suitable for this study.

\section{d. Facilitating Condition}

CFA for the fourth independent variable, Facilitating Condition is performed to analyze how well the measured variables represent the number of constructs. 
International Journal of Managing Public Sector Information and Communication Technologies (IJMPICT) Vol. 6, No. 2, June 2015

Table 9: Indexes Facilitating Condition

\begin{tabular}{|l|l|l|l|}
\hline Fit Indices & Recommended Level** & Output Value & Summary \\
\hline $\mathrm{X}^{2}$ & Not significant $\mathrm{p}>0.05$ & .000 & Not Accepted \\
\hline $\mathrm{X}^{2} / \mathrm{df}$ & $<3.0$ & 8.76 & Not Accepted \\
\hline GFI & $\geq 0.80$ & .96 & Accepted \\
\hline AGFI & $\geq 0.80$ & .81 & Accepted \\
\hline NFI & $\geq 0.80$ & .94 & Accepted \\
\hline CFI & $\geq 0.90$ & .95 & Accepted \\
\hline RMSEA & $<0.10$ & .19 & Not Accepted \\
\hline
\end{tabular}

**Source: Medsker et al. (1994), Doll et al. (1994), Bentler et al. (1995) and Hair et al. (2010)

A CFA is conducted for these constructs to determine whether the indicators measured the constructs and are assigned adequately. Based on Table 9, CFI value (0.95), NFI value (0.94), GFI value (0.96), and AGFI value (0.81) indicates adequate model fit and are acceptable for this study. On the other hand, RMSEA value (0.19) is above the threshold and not indicates a good model for this study.In addition, to ensure that the measurement model fit and suitable for this study, Facilitating Condition indexes are examined. Hair et al. (2010) have suggested that if three or four indexes are accepted, this measurement model is recommended for further analysis. Therefore, as described in Table 9, the model has four accepted indexes that indicate Facilitating Condition measurement model is suitable for this study.

\section{e. Knowledge Sharing Behavior}

CFA for the dependent variable - Knowledge Sharing Behavior is performed to analyze how well the measured variables represent the number of constructs.

Table 10: Indexes Knowledge Sharing Behavior

\begin{tabular}{|l|l|l|l|}
\hline Fit Indices & Recommended Level** & Output Value & Summary \\
\hline$X^{2}$ & Not significant $p>0.05$ & .000 & Not Accepted \\
\hline$X^{2} / \mathrm{df}$ & $<3.0$ & .00 & Accepted \\
\hline GFI & $\geq 0.80$ & 1.00 & Accepted \\
\hline AGFI & $\geq 0.80$ & .00 & Not Accepted \\
\hline NFI & $\geq 0.80$ & 1.00 & Accepted \\
\hline CFI & $\geq 0.90$ & 1.00 & Accepted \\
\hline RMSEA & $<0.10$ & .36 & Not Accepted \\
\hline
\end{tabular}

**Source: Medsker et al. (1994), Doll et al. (1994), Bentler et al. (1995) and Hair et al. (2010)

A CFA is conducted for these constructs to determine whether the indicators measured the constructs and are assigned adequately. As revealed in Table 10, CFI value (1.00), NFI value (1.00), and GFI value (1.00) indicates adequate model fit and are acceptable for this study. On the contrary, AGFI value (0.00) and RMSEA value (0.36) are below the recommended level and not adequate as model fit. Furthermore, to ensure that the measurement model fit and suitable for this study, Knowledge Sharing Behavior indexes are examined. Hair et al. (2010) have suggested that if three or four indexes are accepted, this measurement model is recommended for further analysis. Therefore, as described in summary of Table 10, the model has four accepted indexes that indicate Knowledge Sharing behavior measurement model is reliable and valid for this study. 
International Journal of Managing Public Sector Information and Communication Technologies (IJMPICT) Vol. 6, No. 2, June 2015

\subsection{Hypotheses Testing}

After the measurement model for all variables (factors) are analyzed using CFA and consider as significant, the next step is to analyze the model using Structural Equation Modeling (SEM). SEM is conducted to examine the possibility of achieving goodness-of-fit of the proposed model using Analysis of Moment Structures (AMOS) statistical software.

Maximum Likelihood assumes that the underlying variables are normally distributed. For this study, the maximum likelihood estimates result as describe in Table 11 shows that the standardized residuals are technically fit index, and provide information about how closely the estimated matrix corresponds to the observed matrix and described how well the data fits the model.

Table 11: Maximum Likelihood Estimates Result

\begin{tabular}{|l|l|l|l|}
\hline & Estimate & S.E. & P \\
\hline $\begin{array}{l}\text { Knowledge Sharing Behavior <-- Performance } \\
\text { Expectancy }\end{array}$ & 3.417 & 3.475 & $.000 * *$ \\
\hline Knowledge Sharing Behavior <-- Effort Expectancy & 1.743 & 1.955 & $.00 *$ \\
\hline Knowledge Sharing Behavior <-- Social Influence & .537 & 1.094 & $.000 * *$ \\
\hline Knowledge Sharing Behavior <-- Facilitating Condition & .629 & 1.172 & $.000 * *$ \\
\hline
\end{tabular}

Note: Significant levels: * $\mathrm{p}<.01, * * \mathrm{p}<.001$

To determine the minimum loading necessary to include an item in its respective constructs, the general criteria is accepted items with loading of 0.50 or greater (Hair et al., 2010). As shown in Table 11, this model confirmed that Performance Expectancy and Effort Expectancy constructs have a significant direct relationship with Knowledge Sharing Behavior (with path coefficient of 3.42 and 1.74), and justified that Social Influence (with path coefficient of 0.54) and Facilitating Condition (with path coefficient of 0.63 ) have a positive relationship with Knowledge Sharing Behavior.

Table 12: Indexes Knowledge Sharing Behavior

\begin{tabular}{|l|l|l|l|}
\hline Fit Indices & Recommended Level** & Output Value & Summary \\
\hline $\mathrm{X}^{2}$ & Not significant $\mathrm{p}>0.05$ & 0.00 & Not Accepted \\
\hline $\mathrm{X}^{2} / \mathrm{df}$ & $<3.0$ & 2.89 & Accepted \\
\hline GFI & $\geq 0.80$ & 0.80 & Accepted \\
\hline AGFI & $\geq 0.80$ & 0.70 & Not Accepted \\
\hline NFI & $\geq 0.80$ & 0.74 & Not Accepted \\
\hline CFI & $\geq 0.90$ & 0.81 & Not Accepted \\
\hline RMSEA & $<0.10$ & 0.09 & Accepted \\
\hline
\end{tabular}

**Source: Medsker et al. (1994), Doll et al. (1994), Bentler et al. (1995) and Hair et al. (2010)

Based on Table 12, The GFI value (0.80) proves to be a good-fit-model (Hair et al., 2010). One important index for SEM is the RMSEA (Root Mean-Squared Error Approximation), which is an estimate of fit of the model relative to a saturated model in the population. For RMSEA, a value of about 0.10 or less would indicate a close-fit of the model in relation to the degrees of freedom (Hair et al., 2010). On that note, the RMSEA value (0.09) for this study indicates a significant 
close-fit of model. In addition, to ensure that the measurement model fit and suitable for this study, Knowledge Sharing Behavior indexes as described in Table 12 are examined. Hair et al. (2010) have suggested that if three or four indexes are accepted, this measurement model is recommended and significant. Therefore, as described in summary of Table 12, the model has three out of seven accepted indexes that indicate Knowledge Sharing behavior measurement model is suitable for empirical data of this study.

The value of SEM lies in its ability in showing both the direct and indirect effects between the variables. In light of this, this analysis appears to indicate that Performance Expectancy, Effort Expectancy, Social Influence, and Facilitating Condition factors have direct influences for Knowledge Sharing Behavior. As a conclusion, the overall analysis of SEM is significant to support the hypotheses of this research.

\subsection{Multivariate Analysis of Variance (MANOVA)}

Once the measurement model has been analyzed using SEM, the next step is to analyze the moderator variables. These demographic factors will act as moderators that modify the original relationship between the independent and dependent variables. As recommended by previous scholars, the key outputs of MANOVA analysis would be interpreted using the selected criteria, as follows

i. Box's Test of Equality of Covariance Matrices

This analysis indicates whether research data violates the assumption of homogeneity of variance-covariance matrices (Pallant, 2010). If the Significant (Sig.)value is largerthan 0.001 , then analysis have not violated the assumption (Tabachnick\&Fidell, 2012)

ii. Levene's Test of Equality of Error Variances

This analysis indicates whether data has violated the assumption of equality of variance for that variable or not. In the Sig. Column, this test will look for any values that are lessthan 0.05 (Pallant, 2010).

iii. Multivariate tests

Several multivariate statistics is available in MANOVA programs to test the significance of main effects and interactions, such as Wilks' Lambda, Hotelling's Trace and Pillai's Trace.

iv. Wilks' Lambda

This analysis indicates the value of Wilks' Lambda and its associated significance level. If the significance level is less than 0.05 , then it can conclude that there is a difference among the groups (Pallant, 2010).

v. Tests of Between-Subjects Effects

If the analysis has obtained a significant result on the multivariate test of significance, this provides the justification and permission to investigate further in relation to each of the dependent variables. The most common way of doing this analysis is to apply a Bonferroni adjustment with the significance level that is less than 0.05 (Tabachnick\&Fidell, 2012).

\section{a. Age Differences and Knowledge Sharing Behavior}

A one-way between-groups multivariate analysis of variance is performed to investigate age differences for knowledge sharing behavior. As described in Table 13, the result summary indicates there is insignificant difference between ages on the combined dependent variables. 
International Journal of Managing Public Sector Information and Communication Technologies (IJMPICT)

Vol. 6, No. 2, June 2015

Table 13: MANOVA for Age Differences

\begin{tabular}{|l|l|l|l|}
\hline Fit Indices & Recommended Level $* *$ & Output Value & Summary \\
\hline $\begin{array}{l}\text { Equality of Covariance } \\
\text { Matrices }\end{array}$ & Sig.value $>0.001$ & 0.00 & Not Significant \\
\hline Levene's Test & Sig. value $<0.05$ & 0.08 & Not Significant \\
\hline Wilks' Lambda & Sig. value $<0.05$ & 0.965 & Not Significant \\
\hline Between-subjects effects & Sig. value $<0.05$ & 0.38 & Not Significant \\
\hline
\end{tabular}

**Source: Pallant (2010), Tabachnick\&Fidell (2012) and Cohen (1988)

\section{b. Gender Differences and Knowledge Sharing Behavior}

MANOVA analysis for the second demographic or moderator variable - Gender is performed to analyze how well this variable influences the strength of the relationship with the dependent variable - Knowledge Sharing Behavior.

Table 14: MANOVA for Gender Differences

\begin{tabular}{|l|l|l|l|}
\hline Fit Indices & Recommended Level** & Output Value & Summary \\
\hline $\begin{array}{l}\text { Equality of Covariance } \\
\text { Matrices }\end{array}$ & Sig.value $>0.001$ & 0.214 & Significant \\
\hline Levene's Test & Sig. value $<0.05$ & 0.001 & Significant \\
\hline Wilks' Lambda & Sig. value $<0.05$ & 0.022 & Significant \\
\hline Between-subjects effects & Sig. value $<0.05$ & 0.023 & Significant \\
\hline
\end{tabular}

**Source: Pallant (2010), Tabachnick\&Fidell (2012) and Cohen (1988)

As shown in Table 14, there is a significant difference between gender on the combined dependent variables: $F(4,196)=1.45, p=.022$; Wilks' Lambda $=.98$; partial eta squared $=.00$. When the results for the dependent variables are considered separately, the only difference to reach statistical significance is job function: $F(1,199)=5.29, p=.023$, partial eta squared $=.05$. An inspection of the mean scores indicated that females reported slightly higher levels of knowledge sharing behavior $($ Mean $=3.81$, Std. Deviation $=.085)$ than males $($ Mean $=3.49$, Std. Deviation $=1.09$ ).

This finding supports that gender has a positive effect on the relationship between promoting factor variables with knowledge sharing behavior $(\beta=1.45, \mathrm{p}<.05)$. In addition, the mean scores for this study show that females reported slightly higher levels of knowledge sharing behavior for their job function compared to males. This finding has suggested that, compared to men, women are more people-oriented and concerned about their knowledge sharing behaviors that are related to job function.

\section{c. Experience Differences and Knowledge Sharing Behavior}

MANOVA analysis for the last demographic variable - Experience is performed to analyze how well this variable influences the strength of the relationship with the dependent variable - 
International Journal of Managing Public Sector Information and Communication Technologies (IJMPICT) Vol. 6, No. 2, June 2015

Knowledge sharing Behavior. As described in Table 15, the result summary indicates there is insignificant difference between experiences on the combined dependent variables.

Table 15:MANOVA for Experience Differences

\begin{tabular}{|l|l|l|l|}
\hline Fit Indices & Recommended Level** & Output Value & Summary \\
\hline $\begin{array}{l}\text { Equality of Covariance } \\
\text { Matrices }\end{array}$ & Sig.value $>0.001$ & 0.002 & Significant \\
\hline Levene's Test & Sig. value $<0.05$ & 0.63 & Not Significant \\
\hline Wilks' Lambda & Sig. value $<0.05$ & 0.36 & Not Significant \\
\hline Between-subjects effects & Sig. value $<0.05$ & 0.13 & Not Significant \\
\hline
\end{tabular}

**Source: Pallant (2010), Tabachnick\&Fidell (2012) and Cohen (1988)

\section{CONClusion}

This research has empirically validated the UTAUT model in the context of knowledge sharing behavior through the virtual platforms. The findings of this study offer several significance implications for the research on antecedents of knowledge sharing behavior. Consistent with UTAUT,all independent variables - performance expectancy, effort expectancy, social influence, and facilitating condition - have indicated a positive association with virtual knowledge sharing behavior. On that note, this study has suggested that these factors to promote knowledge sharing behavior through virtual platforms for the respective research organizations. Based on the analysis of this study, the summary of each factors and their ranking in inculcating knowledge sharing behavior is described in Table 16.

Table 16: Factors for Knowledge Sharing Behavior

\begin{tabular}{|c|l|l|l|}
\hline No & Factors & Mean & Percentage \\
\hline 1. & Performance Expectancy & 24.27 & 80.9 \\
\hline 2. & Effort Expectancy & 22.97 & 76.6 \\
\hline 3. & Social Influence & 22.67 & 75.6 \\
\hline 4. & Facilitating Condition & 21.84 & 72.8 \\
\hline
\end{tabular}

As illustrated in Table 16, the most prominent scores for this study derived from the performance expectancy factor (80.9\%), referring to the abilityto obtain significant rewards after using the system (Vankatesh et al., 2003). Thus, performance expectancy is shown to be the strongest predictor or motivator of virtual knowledge sharing behavior. Therefore, it is believed that an individual with high performance expectancy is more likely to adopt this behavior than is an individual with lower performance expectancy. The second important factor raised in this study is the effort expectancy factor $(76.6 \%)$, which described the users' acceptance of the new system, such as virtual platforms are determined by easy-to-use elements and whether the system's user interface is developed based on user needs and justification.

The third factor that can promote virtual knowledge sharing behavior is social influence $(75.6 \%)$. Previous research has pointed out that the social and individual context is crucial for work group success. The social factor also has a significant influence toward senior staff in sharing knowledge due to the recognition or motivational factor that influences the positive culture in the 
organization. For instance, a person might hold the belief that knowledge sharing is good for the organization, that culture makes organization look strong, or the negative perception that a sharing culture will burden their time, and they are uncomfortable to share knowledge. The last factor that is identified by this study is facilitating conditions (72.8\%), which refer to the ability of users to operate and utilize the system and the technology support that is provided by the environment, such as training, helpdesk system, manuals, and documentation. Because this factor has the lowest score, this finding suggests that probably most of the respondents are technologysavvy or already familiar with the virtual environment and platforms. Hence, facilitating conditions that include technology assistance or support are the lowest antecedent for the respondents regarding knowledge sharing behavior through the virtual mode.

In addition to the determinants of knowledge sharing behavior, this research further investigates the moderating effect (age, gender and experience) have on the relationships between the determinants factors with the sharing behavior. The main purpose for examining moderating variables is to understand the inconsistencies of results across research. Moderating variables can neutralize, enhance, or lessen the effect of a relationship (Howell, Dorfman, \& Kerr, 1986) and they can unveil the limitations of explanatory powers (Sun \& Zhang, 2006). Eventually, these findings have proposed the effects of knowledge sharing behavior through virtual platforms are moderated by gender only. The mean scores for this study show that females reported slightly higher levels of knowledge sharing behavior for their job function compared to males. This finding has suggested that, compared to men, women are more people-oriented and concerned about their sharing behaviors that are related to job function. The women probably felt more conscious of task-oriented factors, such as team collaboration and interaction, being important for knowledge sharing behavior.

On the contrary, other moderating factors (age and experience) show an invalid relationship as the moderating variables and indicate insignificant differences with virtual knowledge sharing behavior. For instance, this result has proposed no differences between younger or junior respondents with elder or senior respondents in knowledge sharing practices. A possible justification for these findings is that the technical features used in virtual platforms are quite simple and low in cost to be adopted; thus, anyone can familiarize themselves with the system features and tools. In fact, the technical features of the virtual platforms, which includes instant messaging, chat rooms, online forums, blogs and online databases, are simple to use and also available everywhere through the widespread use of social media and common web-based technologies. As indicated by Adams et al. (1992) and Davis et al. (1989), ease-of-use for any technology or system might be a significant determinant of behavioral intention during the early stages of usage, and this attribute could have a greater impact in applications that are more sophisticated and complex.

\section{IMPLICATION AND LIMITATIONS OF THE STUDY}

Eventually, based on UTAUT model, this research has investigated the antecedents of knowledge sharing behavior through the virtual platforms. This research hasalso focus on identifying gaps that would assist in effectively guide government and private sectors in Malaysia, to be more competitive and innovative. This research has both academic and practical implications, such as identifying knowledge sharing holistic initiatives asa vehiclefor success in creating valuable organizational development practices. Furthermore, this study has contributed to the body of knowledge especially in the knowledge sharing field by proposing a suitable theoretical or conceptual model (using UTAUT model) for knowledge sharing behavior. This research also 
International Journal of Managing Public Sector Information and Communication Technologies (IJMPICT) Vol. 6, No. 2, June 2015

contributes to knowledge sharing literature because it provides a potential measurement of the organizational, technological, social, and individual behavior factors that are likely to contribute to knowledge sharing success and acceptance based on the literature review.

The analysis approach used in this research suits the formative and exploratory subjects addressed in the objective of this study. However, several limitations are worth mentioning in this study. For instance, the use of 510 participants from five Research and Development (R\&D) organizations in Government-Linked Companies (GLCs) are only meant for sampling and does not described the whole population of research organization in Malaysia. Furthermore, the sizes of samples from the five GLCs agencies in one country (Malaysia) limited the possibility of this research generalization claim and maybe these participants would perceive the knowledge platform utilization differently from other respondents in different sectors or in other countries. Although there are several limitations, but this research has successfully executed and achieved the proposed objectives.

As recommendation for future research, it would be necessary to conduct study with similar objectives within companies of different sectors, develop more respondents and eventually use other methods or models for data collection and sampling. In addition, it is recommended that this research is repeated in other contexts or in different countries and other kinds of knowledge platform which could complement other recent knowledge sharing studies that are related to the objective of this research.

\section{ACKNOWLEDGEMENTS}

This study was supported by Faculty of Information Management, UniversitiTeknologi MARA, Shah Alam, Malaysia. Also warm appreciation to respondents from Petronas, TenagaNasionalBerhad, Nuclear Malaysia, SIRIM and Green Tech Malaysia for their assistance and cooperation in providing the data and information.

\section{REFERENCES}

[1] Argote, L., Ingram, P., Levin, J. M., and Moreland, R. L. (2000). Organizational learning: Creating, retaining, and transferring knowledge. Boston, MA: Kluwer Academic Publishers.

[2] Bentler, P. (1995). EQS structural equation program manual. Encino, CA: Multivariate Software Inc

[3] Creswell, J. W. (2009). Research design: Qualitative, Quantitative, And Mixed Methods Approaches. Sage Publications, Incorporated.

[4] Davenport, T.H. and L. Prusak (1998). Working Knowledge: How Organizations Manage What They Know. Harvard Business School Press, Boston, MA.

[5] Davis, F. D. (1989). Perceived Usefulness, Perceived Ease of Use and User Acceptance of Information Technologies. MIS Quarterly 13 (3), 319-340.

[6] Davis, F. D., Bagozzi, R. P. and Warshaw, P. R. (1992). Extrinsic and instrinsic motivation to use computers in the workplace. Journal of Applied Social Psychology, 22,1111-1132

[7] Doll, W.J., Xia, W. and Torkzadeh, G. (1994), A confirmatory factor analysis of the end-user computing satisfaction instrument, MIS Quarterly, Vol. 18 (4), 43-461.

[8] Grant, R. M. (1996). Toward a knowledge-based theory of the firm. Strategic management journal, 17, 109-122.

[9] Hair, J. F., Anderson, R. E., Tatham, R. L. and Black, W. C. (2010). Multivariate Data Analysis: A Global Perspective (7th ed). Pearson Prentice-Hall, Upper Saddle River, NJ.

[10] Hartwick, J., \&Barki, H. (1994). Explaining the role of user participation in information system use. Management Science, 40 (4), 440-465. 
International Journal of Managing Public Sector Information and Communication Technologies (IJMPICT) Vol. 6, No. 2, June 2015

[11] Howell, J.P., P.W. Dorfman\& S. Kerr. (1986). Moderator variables in leadership research. The Academy of Management Review, 11 (1), 88-102.

[12] Huber, G. P. (1991). Organizational learning: The contributing processes and the literatures. Organization science, 2(1), 88-115.

[13] Ismail Manuri\& Raja Abdullah Yaacob. (2011). Strategizing knowledge management in the Malaysian Armed Forces: Towards knowledge-centric organization. Journal Information and Knowledge Management, 1 (1), 19-36.

[14] Karahanna, E., \& Straub, D. W. (1999). The psychological origins of perceived usefulness and easeof-use. Information and Management, 35 (4), 237-250

[15] Krejcie, R. V., and Morgan, D. W. (1970). Determining Sample Size for Research Activities. Educational and Psychological Measurement, 607-610.

[16] Lin, H. F. (2008). Determinants of Successful Virtual Communities: Contributions from System Characteristics and Social Factors. Information \& Management 45 (8), 2008, pp. 522-527.

[17] Marchewka, J. T., Liu, C., \&Kostiwa, K. (2007). An application of the UTAUT model for understanding student perceptions using course management software. Communications of the IIMA, 7(2), 93-104.

[18] Massey, A. P., Montoya-Weiss, M. M., and O'Driscoll, T. M. (2002). Knowledge management in pursuit of performance: Insights from Nortel Networks. Mis Quarterly, 269-289.

[19] Medsker G.M., Williams L.J. and Holohan P. (1994). A review of current practices for evaluating causal models in organizational behavior and human resources management research. J. Manage. 20:439-64

[20] Moran, M., Hawkes, M., \& El Gayar, O. (2010). Tablet personal computer integration in higher education: Applying the Unified Theory of Acceptance and Use Technology model to understand supporting factors. Journal of Educational Computing Research, 42 (1), 79-101.

[21] Pallant, J. (2010). SPSS Survival Manual: A step by step guide to data analysis using SPSS. New York: McGraw-Hill International.

[22] Raykov, T., and Marcoulides, G. A. (2008). An introduction to applied multivariate analysis. CRC Press.

[23] Ryan, A. B. (2006). Post-positivist approaches to research. Researching and Writing your Thesis: a guide for postgraduate students, 12-26.

[24] Sekaran, U. (2006). Research methods for business: A skill building approach. Wiley. com.

[25] Sun, H., \& Zhang, P. (2006). The role of moderating factors in user technology acceptance. International Journal of Human-Computer Studies, 64 (2), 53-78.

[26] Tabachnick, B. G., \&Fidell, L. S. (2012). Using multivariate statistics: International edition. California: Pearson Education.

[27] Venkatesh, V., \&Bala, H. (2008). Technology Acceptance Model 3 and a research agenda on interventions. Decision Sciences, 39 (2), 273-315.

[28] Venkatesh, V., \& Davis, F. D. (2000). Theoretical Extension of the Technology Acceptance Model: Four Longitudinal Field Studies. Management Science, 46(2), 186-204.

[29] Venkatesh, V., Morris, M.G.., Davis, G. B., Davis, F. D, (2003). User Acceptance of Information Technology: Toward A Unified View. MIS Quarterly 27 (3), 425-478.

[30] Venkatesh, V., Thong, J. Y. L., \&Xu, X. (2012). Consumer acceptance and use of information technology: Extending the Unified Theory of Acceptance and Use of Technology. MIS Quarterly, 36 (1), 157-178. 
International Journal of Managing Public Sector Information and Communication Technologies (IJMPICT)

Vol. 6, No. 2, June 2015

\section{Author}

This author is from Faculty of Information Management, UniversitiTeknologi MARA, Shah Alam, Malaysia. Born in Kampar, Perak on 12 April 1974. He received his first degree (Bachelor in Information Technology) from Universiti Utara Malaysia (graduated in 1998) and pursued his study in UniversitiTeknologi Mara, Shah Alam, Malaysia in Master in Information Technology, from 2003 until 2007. He had 11 years of experience during his job with Petroleum NasionalBerhad (PETRONAS) as Senior Executive in Information and Technology (IT) field and continues his career

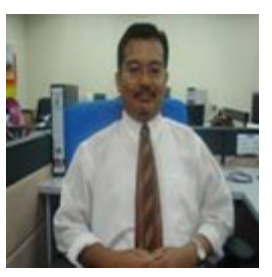
in Telekom Malaysia as Senior Audit Manager for about 2 years. Currently he is pursuing his full time Doctoral Degree (PhD) study in UniversitiTeknologi Mara, Shah Alam Malaysia for his research entitle Factors Promoting Knowledge Sharing Using Virtual Mode Among Researchers In Government-Linked Companies.HairolAdenanKasim had already presented his research in various occasions and proceedings Academic Colloquium in Information Science and Information Management in SukhothaiThammathirat Open University (September 2012), International Conferences on Social Science Research Penang, Malaysia (July 2013), International Symposium on Information Science and Information Management (November 2013) in Bangkok, Thailand and World Congress of Muslim Librarians and Information Scientists (February 2014) in Shah Alam, Malaysia. 